А. В. Малиновський, А. С. Ставничий, М. Н. Майоренко

Одеський національний медичний університет

\title{
ПЕРЕВАГИ СУЧАСНИХ СИМУЛЯЦЙНИХ І МУЛЬТИМЕДІЙНИХ ТЕХНОЛОГІЙ У ВИКЛАДАННІ ХІРУРГІЧНИХ ХВОРОБ I ЕНДОСКОПІЧНОЇ ХІРУРГІЇ СТУДЕНТАМ ТА КУРСАНТАМ ПІСЛЯДИПЛОМНОЇ ОСВІТИ
}

\author{
A. V. Malinovskiy, A. S. Stavnichy, M. N. Mayorenko \\ Odesa National Medical University

\begin{abstract}
ADVANTAGES OF MODERN SIMULATION AND MULTIMEDIA TECHNOLOGIES IN TEACHING SURGICAL DISEASES AND
\end{abstract} \\ ENDOSCOPIC SURGERY FOR STUDENTS AND POSTGRADUATES
}

\begin{abstract}
Мета роботи - оцінка ефективності застосування сучасних симуляційних та мультимедійних технологій у викладанні хірургічних хвороб і ендоскопічної хірургії студентам та курсантам післядипломної освіти.

Основна частина. На кафедрі роботизованої і ендоскопічної хірургії Одеського національного медичного університету був впроваджений в рутинне використання комплекс для симуляційного навчання і трансляції з операційної. Можливості цих технологій були апробовані в ході занять зі студентами студентського наукового гуртка, на елективному циклі “Ендоскопічні втручання в медицині” та при проведенні тематичних удосконалень для лікарів “Основи лапароскопічної хірургії”.

На прикладі опрацьованих практичних навичок була продемонстрована висока ефективність даного виду навчання. У процесі проведення занять значних труднощів у використанні як системи трансляції, так і відпрацювання навичок на віртуальних симуляторах і тренажерах не спостерігалося.

Висновки. 1. Використання системи трансляції ендоскопічних операцій з двостороннім аудіозв'язком з аудиторією дозволяє поліпшити демонстративність при проведенні занять зі студентами.

2. Використання віртуальних симуляторів Simbionix і тренажерів SimuLab при проведенні післядипломних тематичних удосконалень і практичних занять зі студентами високоефективні в засвоєнні практичних навичок ендоскопічної хірургії.

3. Необхідно використовувати єдиний комплекс практичних навичок та теоретичної частини, що відповідає світовим стандартам.
\end{abstract}

Ключові слова: лапароскопічна хірургія; симуляційне навчання; практичні навички; трансляція операцій.

The aim of the work - to evaluate the effectiveness of the use of modern simulation and multimedia technologies in practical training of students and postgraduates.

The main body. The simulation training and translation of procedures was introduced to routine use at the Department of Robotic and Endoscopic Surgery of Odesa National Medical University. The possibilities of these technologies were tested during practical classes in the students' surgical club and on elective course of Endoscopic Surgery, and during postgraduate courses for doctors "Fundamentals of Laparoscopic Surgery".

High efficiency of this type of training was demonstrated. During the course of the training, there were no significant difficulties in using of both translation system and the simulation training.

Conclusions. 1. The use of translation system of endoscopic procedures with two-way audio communication with the audience allows to improve demonstrativeness of the practical classes.

2. Using of Simbionix virtual simulators and SimuLab training boxes in postgraduate courses and practical exercises with the students showed its high effectiveness in mastering the practical skills of endoscopic surgery.

3. It is necessary to use a combination of practical skills and theoretical part, according to world standards.

Key words: laparoscopic surgery; simulation training; practical skills; translation of surgeries.

Вступ. У даний час у більшості європейських медичних університетів і навчальних центрів для лікарів використовуються сучасні технології у викладанні хірургічних дисциплін. До них відносяться різні мультимедійні технології і симуля-

(c) А. В. Малиновський, А. С. Ставничий, М. Н. Майоренко ційне навчання. Серед мультимедійних технологій викладання хірургічних дисциплін найбільш ефективними $є$ трансляція операцій в аудиторію 3 двостороннім аудіозв'язком хірурга 3 аудиторією. 3 симуляційних технологій найціннішою для освоєння практичних навичок лапароскопічної та 
ендоскопічної хірургії є використання віртуальних симуляторів і тренажерів з відеокамерою.

Мета роботи - оцінка ефективності застосування сучасних симуляційних та мультимедійних технологій у викладанні хірургічних хвороб і ендоскопічної хірургії студентам та курсантам післядипломної освіти.

Основна частина. На кафедрі роботизованої і ендоскопічної хірургії Одеського національного медичного університету був впроваджений в рутинне використання комплекс для симуляційного та мультимедійного навчання. Система трансляції з операційної в аудиторію включає: ретранслятор відеосигналу в аудиторію ExpandOR (США), що підключається до HD-лапароскопічної стійки Karl Stortz (Німеччина) або до HD-камери зовнішнього вигляду Simeon (Туреччина); аналогічний ретранслятор відеосигналу, що знаходиться в аудиторії; гарнітурний радіомікрофон Shure (Німеччина), підключений до ретранслятора; систему передачі цифрового сигналу за допомогою кабелю (Ethernet) і відповідні блоки по обидва боки (з боку операційної та з боку аудиторії); HD-відеомонітор з аудіоколонками в аудиторії; систему радіомікрофонів Shure (Німеччина) в аудиторії (рис. 1). Оскільки зазначені ретранслятори дозволяють передавати аудіосигнал тільки в односторонньому напрямку, звук з операційної (з гарнітури мікрофона) передавався за допомогою них, а звук з аудиторії (з радіомікрофонів) передавався через інтернетзв’язок за допомогою програми Skype (для цього використовували комп’ютер, мобільний телефон і комп’ютерні аудіоколонки). Підключення та налаштування системи займало в середньому 30 хв. Відстань між операційною та аудиторією становила близько 100 м. В основному демонструвалися лапароскопічні операції.

Симуляційний комплекс кафедри включає віртуальні симулятори Simbionix (США) і лапароскопічні тренажери SimuLab (США). Кафедра має віртуальні симулятори за всіма видами малоінвазивних оперативних втручань: симулятор лапароскопічних операцій LapMentor; симулятор ендоскопічних втручань BronchGIMentor (гастро-, колоно-, бронхоскопія); симулятор резектоскопічних (гінекологічних та урологічних втручань HystMentor); симулятор урологічних ендоскопічних і черезшкірних втручань UroPercMentor (рис. 2). Ці симулятори дозволяють не тільки бачити втручання, що імітується, на моніторі, а й при маніпуляціях інструментами відтворюють тактильні відчуття; при цьому

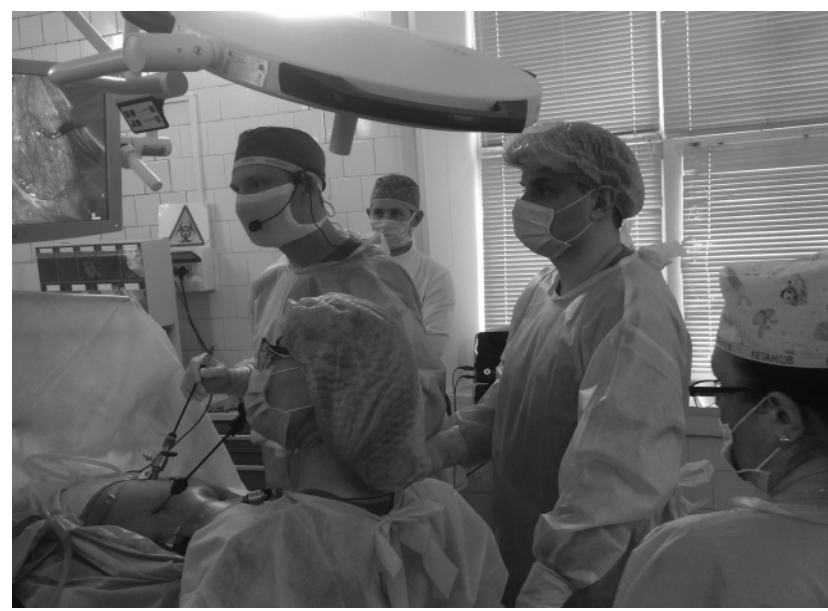

Рис. 1. Проведення заняття з курсантами при проведенні тематичного удосконалення “Основи лапароскопічної хірургії” з трансляцією операцій.

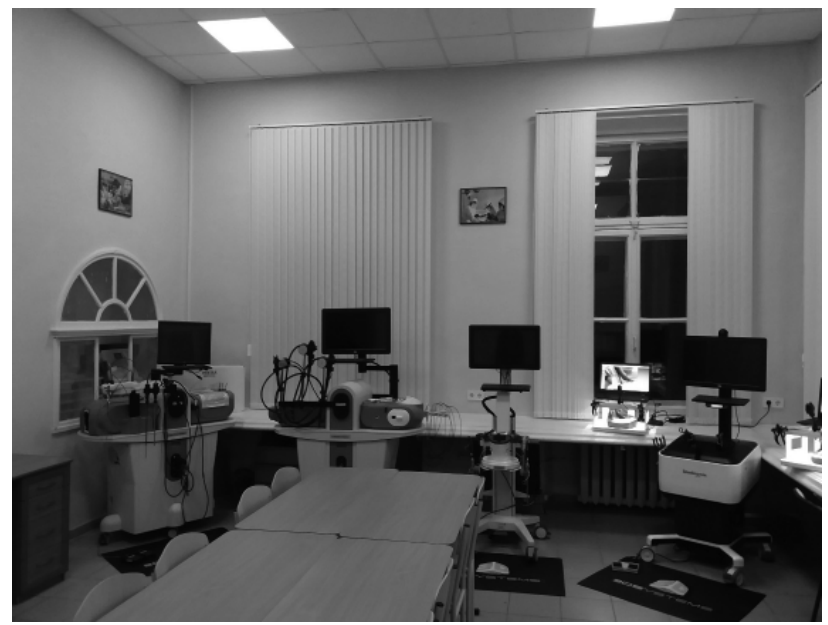

Рис. 2. Симуляційний клас кафедри.

самі інструменти повністю відповідають реальним. Віртуальні симулятори мають велику кількість модулів як за базовими навичками, так і за етапами певних операцій.

Тренажери для відпрацювання лапароскопічних навичок забезпечені веб-камерами з автофокусом і ноутбуками з моніторами високої роздільної здатності, а також всіма необхідними інструментами і різними моделями. На них можна відпрацьовувати такі базові навички, як, наприклад, перекладання кілець, і такі складні навички, як пластика стравохідного отвору діафрагми або ревізія холедоха. Для цього використовуються спеціальні силіконові органні моделі (рис. 3). Таким чином, даний комплекс повністю відповідає світовим вимогам до навчання в ендоскопічній хірургії.

Можливості зазначених мультимедійних і віртуальних технологій апробовані в ході занять 3 членами студентського наукового гуртка кафедри, 


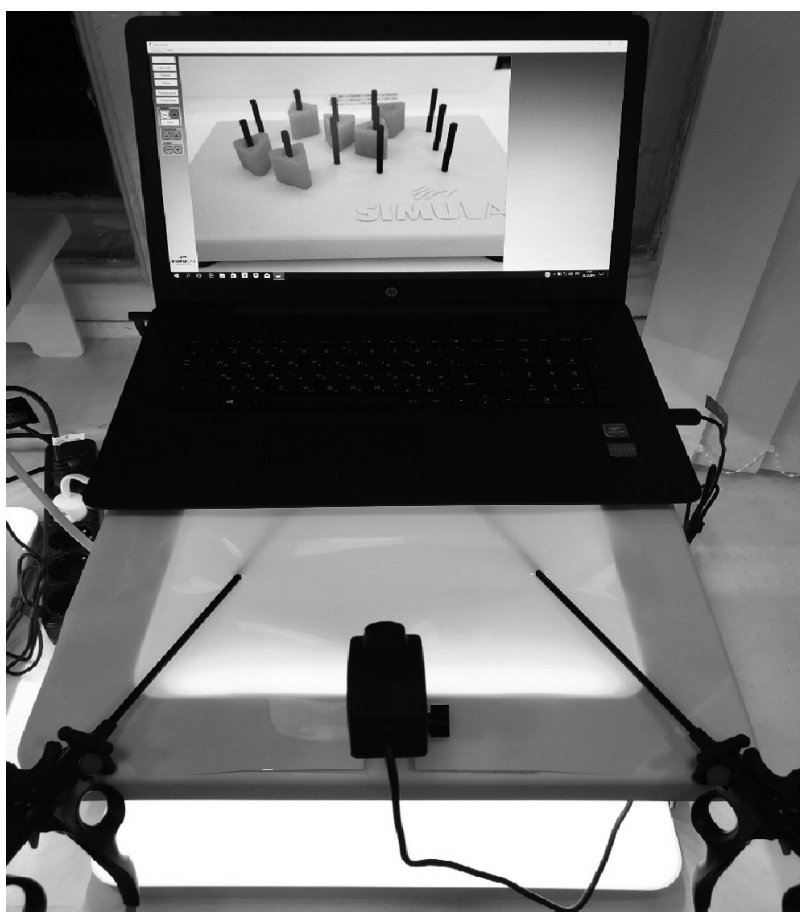

Рис. 3. Тренажер Simulab.

практичних занять зі студентами 6-го курсу на елективному циклі “Ендоскопічні втручання в медицині” та при проведенні тематичних удосконалень для лікарів “Основи лапароскопічної хірургії” (рис. 4). Також комплекс успішно використовувався при проведенні двох науково-практичних конференцій: на одній використовувалася і трансляція операцій на біомоделях і у пацієнтів, і демонстрація на симуляторах, на другій - тільки демонстрація на симуляторах. Кафедра провела два цикли тематичного удосконалення для лікарів. Перший пробний триденний курс був проведений спільно 3 кафедрою симуляційної медицини, в той час як другий 36-годинний був проведений повністю на кафедрі роботизованої та ендоскопічної хірургії. При цьому курсанти брали участь в операціях або перебували в аудиторії з налагодженою трансляцією і двостороннім зв'язком; займалися на віртуальних симуляторах і тренажерах не менше 12 годин, а також прослухали 5 лекцій. Така побудова курсу повністю відповідає міжнародним стандартам післядипломної освіти.

Вивчення ступеня засвоєння вищевказаних практичних навичок проводилося за 10-бальною візуальною аналоговою шкалою. При цьому 0 балів відповідали повній неможливості відтворити практичну навичку, а 10 балів відповідали можливості відтворити практичну навичку так, як їі демонстрував викладач. У досліжденні брали

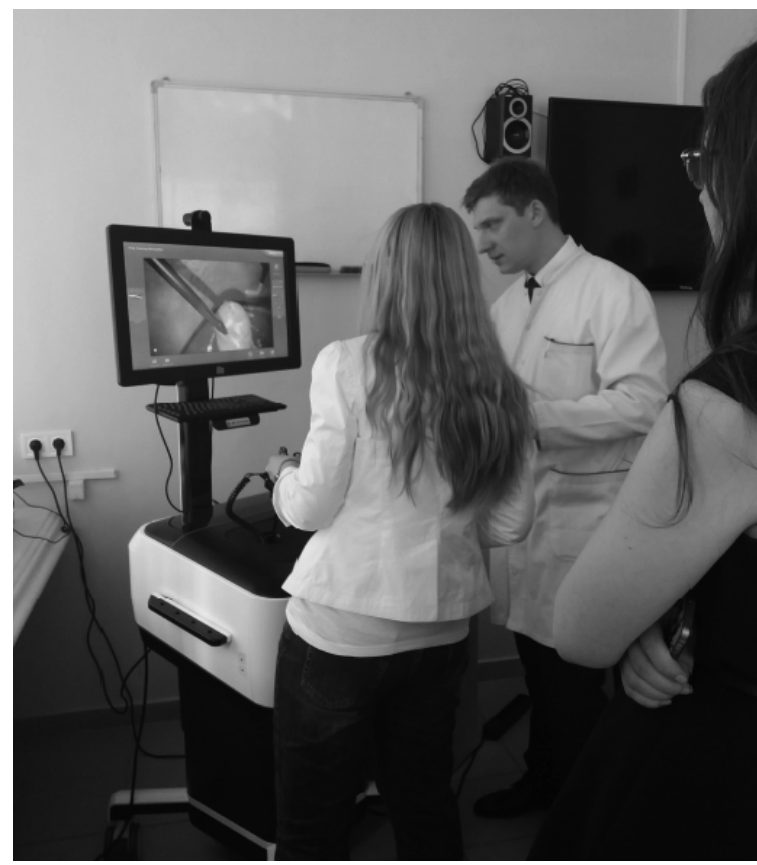

Рис. 4. Проведення заняття на віртуальному симуляторі Simbionix.

участь 43 студенти та курсанти. При вивченні ступеня засвоєння базової практичної навички перекладання кілець на тренажері SimuLab до занять середній бал склав $(1,5 \pm 1,2)$ бала, після проведення занять - $(6,7 \pm 1,8)$ бала $(\mathrm{p}<0,05)$. При освоєнні практичної навички кліпування судинних структур на симуляторі LapMentor до навчання середній бал склав $(2,1 \pm 1,6)$ бала, після навчання - $(8,3 \pm 1,2)$ бала $(\mathrm{p}<0,05)$. Таким чином, на прикладі двох з 15 опрацьованих практичних навичок була продемонстрована висока ефективність даного виду навчання. У процесі проведення занять значних труднощів у використанні як системи трансляції, так і відпрацювання навичок на тренажерах і симуляторах не спостерігалося.

Історія системи навчання практичних навичок в ендоскопічній хірургії включає різні методики, серед яких найбільш ефективними виявилася асистенція на операціях курсантів і відпрацювання практичних навичок на тренажерах і віртуальних симуляторах [3]. Для навчання студентів старших курсів, замість асистенції в операційній, достатньо налагодити трансляцію з операційної, що дозволяє, з одного боку, виключити перебування студентів в операційній залі, з іншого - залучити всю групу в процес навчання. Двосторонній аудіозв’язок з аудиторією значно розширює можливості такої демонстрації. Існують різні симулятори лапароскопічних операцій, принцип роботи яких полягає в імітації 
маніпуляцій лапароскопічних інструментів, проте не всі з них мають великий набір навчальних модулів (від початкового до просунутих) і функцію зворотного тактильного зв'язку [1, 2]. Симулятор Simbionix $є$ світовим лідером у цій технології, маючи всі зазначені переваги [1, 2]. За даними літератури, функція зворотного тактильного зв'язку (Haptic Feedback) є однією з найбільш цінних для формування стереотипу рухів і дозволяє швидко й ефективно приступити до виконання реальних операцій $[4,5]$. Велике значення також має наявність повного комплексу симуляторів за всіма розділами малоінвазивної хірургії: лапароскопічного, ендоскопічного, урологічного та гінекологічного. Тренажери для відпрацювання лапароскопічних навичок пройшли певну еволюцію, і найкращими серед них $є$ тренажери SimuLab. Їх перевагою $\epsilon$ простота використання і великий вибір моделей для відпрацювання навичок від найпростіших до найскладніших (силіконові органні моделі для відпрацювання окремих етапів операцій). Причому обидва види симуляторів доповнюють один одного, як за базовими навичками, так і за операціями.

Наш невеликий досвід показав, що найбільш цінним, особливо для післядипломної освіти, $є$ об’єднання практичної частини з теоретичною частиною. Практична частина полягає в асистенції в операційній (що може бути замінено трансляцією) i роботі на зазначених симуляторах. Теоретична частина складається з лекцій експертів з найбільш важливих питань. За таким принципом працює більшість міжнародних навчальних центрів, а ефективність такого принципу навчання підтверджена низкою наукових праць [1-3]. Відзначимо, що навчальний центр, організований на кафедрі роботизованої і ендоскопічної хірургії, що працює за вищевказаними принципами, не має аналогів в Україні.

Висновки. 1. Використання системи трансляції ендоскопічних операцій 3 двостороннім аудіозв’язком 3 аудиторією дозволяє поліпшити демонстративність при проведенні практичних занять зі студентами.

2. Використання віртуальних симуляторів Simbionix і тренажерів SimuLab при проведенні післядипломних тематичних удосконалень і практичних занять зі студентами високоефективні в засвоєнні практичних навичок ендоскопічної хірургії.

3. Необхідно використовувати єдиний комплекс практичних навичок та теоретичної частини, що відповідає світовим стандартам.

\section{Список літератури}

1. Alaker M. Virtual reality training in laparoscopic surgery: A systematic review \& meta-analysis / M. Alaker, G. R. Wynn, T. Arulampalam // International Journal of Surgery. - 2016. Vol. 29. - P. 85-94. DOI: 10.1016/j.ijsu.2016.03.034.

2. Barsom E. Z. Systematic review on the effectiveness of augmented reality applications in medical training / E. Z. Barsom, M. Graafland, M. P. Schijven // Surgical Endoscopy. - 2016. - Vol. 30 (10). - P. 4174-4183. DOI: 10.1007/s00464-016-4800-6.

3. A scoping review of assessment tools for laparoscopic suturing / E. Bilgic, S. Endo, E. Lebedeva [et al.] // Surgi-

\section{References}

1. Alaker, M., Wynn, G.R., \& Arulampalam, T. (2016). Virtual reality training in laparoscopic surgery: A systematic review \& meta-analysis. International Journal of Surgery, 29, 85-94. DOI: 10.1016/j.ijsu.2016.03.034.

2. Barsom, E.Z., Graafland, M., \& Schijven, M.P. (2016). Systematic review on the effectiveness of augmented reality applications in medical training. Surgical Endoscopy, 30 (10), 4174-4183. DOI: 10.1007/s00464-016-4800-6.

3. Bilgic, E., Endo, S., Lebedeva, E., Takao, M., McKendy, K.M., Watanabe, Y., ... Vassiliou, M.C. (2018). cal Endoscopy. - 2018. - Vol. 3. - P. 1-15. DOI: 10.1007/ s00464-018-6199-8.

4. A review of simulators with haptic devices for medical training / D. Escobar-Castillejos, J. Noguez, L. Neri [et al.] // Journal of Medical Systems. - 2016. - Vol. 40 (4). P. 104. DOI: 10.1007/s10916-016-0459-8.

5. Pinzon D. Prevailing trends in haptic feedback simulation for minimally invasive surgery / D. Pinzon, S. Byrns, B. Zheng // Surgical Innovation. - 2016. - Vol. 23 (4). P. 415-421. DOI: 10.1177/1553350616628680.

A scoping review of assessment tools for laparoscopic suturing. Surgical Endoscopy, 3, 1-15. DOI: 10.1007/s00464018-6199-8.

4. Escobar-Castillejos, D., Noguez, J., Neri, L., Magana, A., \& Benes, B. (2016). A review of simulators with haptic devices for medical training. Journal of Medical Systems, 40 (4), 104. DOI: 10.1007/s10916-016-0459-8.

5. Pinzon, D., Byrns, S., \& Zheng, B. (2016). Prevailing trends in haptic feedback simulation for minimally invasive surgery. Surgical Innovation, 23 (4), 415-421. DOI: 10.1177/1553350616628680. 